\title{
A expansão da educação superior no Brasil: notas sobre os desafios do trabalho docente
}

\author{
The expansion of higher education in Brazil: \\ notes on the challenges for teaching work
}

\begin{abstract}
Caroline Broch ${ }^{1}$ - Centro Universitário de Maringá | Departamento de Educação Física | Maringá | PR | Brasil. Contato: carolinebroch@yahoo.com.br. ORCID: https://orcid.org/0000$\underline{0002-6140-6798}$
\end{abstract}

Fabiane Castilho Teixeira Breschiliare ${ }^{2}$ - Universidade Federal de Santa Catarina |
Departamento de Educação Física | Florianópolis | SC | Brasil. Contato:
fabianecteixeira@gmail.com. ORCID: $\underline{\text { https://orcid.org/0000-0002-0822-2340 }}$

Ieda Parra Barbosa-Rinaldi ${ }^{3}$ - Universidade Estadual de Maringá | Departamento de Educação Física | Maringá | PR | Brasil. Contato: parrarinaldi@ hotmail.com. ORCID: https://orcid.org/0000-0003-1258-7155

Resumo: Esta pesquisa documental objetivou apresentar o cenário da expansão da educação superior no Brasil e seus desafios para o trabalho docente. Para tanto, utilizamos como fonte de dados o sítio virtual do INEP e do MEC, e as Sinopses Estatísticas do Censo de Ensino Superior. Os resultados indicaram que, no lastro da expansão das instituições, matrículas, cursos e funções docentes nas últimas décadas, o crescimento se deu, majoritariamente, pelo setor privado. Juntamente com a expansão desordenada da educação superior, prejuízos para o trabalho docente foram agregados em virtude das novas funções a ele atribuídas. Isso traz à tona desafios à educação superior que precisam ser problematizados e pressupõem implicações para todo o sistema educacional brasileiro.

Palavras-chave: Educação superior. Trabalho docente. Instituições de ensino superior.

\begin{abstract}
This documentary research aimed to present the scenario of the expansion of higher education in Brazil and its challenges to the teaching work. For this, we used data source the INEP and MEC virtual site, and the Statistical Synopses of the Higher Education Census. The results indicated that, in the context of the expansion of institutions, enrollments, courses and teaching functions in the last decades, the growth was mainly by the private sector. Along with the disorderly expansion of higher education, impairments to the teaching work were aggregated by virtue of the new functions assigned to it. This brings up challenges to higher education that need to be problematized and implications for the educational system in Brazil.
\end{abstract}

Keywords: Higher Education. Teaching work. Institution of Higher Education.

- Recebido em: 20 de maio de 2020 • Aprovado em: 25 de maio de 2020

DOI: http://dx.doi.org/10.1590/S1414-4077/S1414-40772020000200002

Este é um artigo publicado em acesso aberto sob uma licença Creative Commons

https://creativecommons.org/licenses/by-nc/4.0/ 


\section{Introdução}

A educação superior no Brasil é ofertada por um conjunto ampliado de Instituições de Ensino Superior (IES), de caráter público e privado, devidamente normatizadas na Constituição Federal de 1988 e na Lei de Diretrizes e Bases da Educação Nacional (LDB Lei $\mathrm{n}^{\circ}$ 9.394/1996) ${ }^{1}$ (BRASIL, 1996), além de contar com um vasto aparato de decretos, regulamentos e portarias $^{2}$.

Nas últimas décadas, a educação superior expandiu-se no contexto nacional, o que provocou modificações em sua estrutura, com novos níveis e modalidades de educação ${ }^{3}$, com a ampliação da admissão de docentes, o aumento da oferta de cursos e do número de alunos matriculados, além do surgimento de novas instituições (SANTOS; SIMÕES, 2008).

Isso foi possível, sobretudo, com a elaboração do Plano Nacional de Educação - PNE 2001-2010, no final da década de 1990. Nesse documento, constavam 295 metas para a educação, sendo 35 para a educação superior revelando uma preocupação com a expansão deste nível de ensino e propondo o aumento da oferta de vagas e de matrículas, além da diversificação do sistema pelo estímulo ao desenvolvimento da Educação à Distância e a institucionalização de um sistema nacional de avaliação.

Nesse mesmo cenário, a $\mathrm{UNESCO}^{4}$ promoveu debates e organizou documentos específicos, a fim de pensar nesse conjunto de novos desafios para a educação superior em nível mundial. No documento "Declaração Mundial sobre Educação Superior no Século XXI: Visão e Ação" (UNESCO, 1998), a educação superior é compreendida como lócus de formação de indivíduos críticos, qualificados e cultos, contribuindo para o desenvolvimento sustentável de um país.

Posteriormente, o texto "Desafios e perspectivas da educação superior brasileira para a próxima década 2011-2020" (UNESCO, 2012), aponta para a complexidade dos desafios da educação superior brasileira, tendo em vista a política de expansão de vagas e de promoção da qualidade, para ampliar a democratização e a relação da universidade com a sociedade.

\footnotetext{
${ }^{1}$ Convém destacar que, a Lei 13.868/19 altera a LDB (Lei 9.394/96), e incorpora as universidades comunitárias entre as instituições de ensino superior. No entanto, considerando o período em que a análise deste estudo foi realizada, foram contempladas as IES públicas e privadas, que já estavam previstas na LDB.

${ }^{2}$ As IES públicas são mantidas pelo Poder Público, nas formas: Federal, Estadual ou Municipal. Já as IES privadas são administradas por pessoas físicas ou jurídicas de direito privado, com fins lucrativos ou sem fins lucrativos (comunitárias, confessionais, filantrópicas).

${ }^{3}$ Como a modalidade de Ensino a Distância (EaD).

${ }^{4}$ Agência especializada da ONU (Organização das Nações Unidas), responsável pela cooperação internacional nos campos educacional, cultural e científico.
} 
Outro importante documento organizado foi o Plano Nacional de Educação (PNE 2014-2024), em que foram fixadas 20 metas para a educação, sendo três voltadas especificamente para a educação superior (metas 12, 13 e 14). Esse documento pontuou uma série de desafios para as políticas públicas brasileiras e apresentou indicativos de ações a serem adotadas pelos entes federais, com a finalidade de consolidar um sistema educacional qualificado.

Ao passo que o Brasil ampliou o acesso à educação superior, antes reservado às classes mais altas, é possível presenciar nos dias de hoje um amplo processo de privatização deste nível de ensino (FRANCO; DAL POZ, 2018; SGUISSARD, 2015; BARREYRO, 2008). Ademais, dados do INEP (2015) revelaram que, aproximadamente, $88 \%$ de IES no Brasil são privadas.

Assim sendo, o artigo objetivou apresentar o cenário da expansão da educação superior no Brasil e seus desafios para o trabalho docente. Para dar conta do objetivo proposto, o texto foi organizado em três seções: a primeira trata da contextualização da educação superior no Brasil; a segunda apresenta os indicadores gerais dessa expansão após a década de 1990; e a terceira discute os desafios atuais para o trabalho docente.

\section{Decisões metodológicas}

Para o desenvolvimento do estudo que deu origem a este artigo recorremos aos recursos da pesquisa documental (ALMEIDA SANTOS, 2006; LAKATOS; MARCONI, 2012), tendo como fonte empírica os sítios do Instituto Nacional de Estudos e Pesquisas Educacionais Anísio Teixeira (INEP), do Ministério da Educação (MEC).

Consultamos os dados do Resumo Técnico e das Sinopses Estatísticas do Censo da Educação Superior publicados no período de 1995 a 2015. Estes documentos reúnem as principais informações sobre instituições, recursos humanos, cursos de graduação, matrículas, ingressantes, concluintes, além de informações sobre docentes nas formas de categoria administrativa (pública/privada). Além disso, apresentam planilhas separadas por modalidades de ensino (presencial e EaD). Portanto, para essa pesquisa, optamos por um refinamento dos dados na modalidade presencial. As buscas foram realizadas no mês de junho de 2017 e revisitadas em julho de 2018. Além dos dados quantitativos compilados a partir das Sinopses Estatísticas e do Resumo Técnico, também consultamos documentos produzidos pelo INEP para analisar a contextualização da educação superior no Brasil, quais sejam: Educação superior: conceitos, definições e classificações (2000); Evolução do Ensino Superior Graduação 1980-1998 (2000); Educação Superior Brasileira: 1991-2004 (2006); 
Modelos Institucionais de Educação Superior (2006); e Mapa do ensino superior privado (2008). Por fim, recorremos às seguintes legislações: Lei da Reforma Universitária de 1968; Constituição da República Federativa do Brasil de 1988; Lei de Diretrizes e Bases da Educação Nacional (1996).

Para tratamento do material empírico, os dados foram organizados em tabelas, gráficos e quadros e analisados com base na estatística descritiva simples, representados em percentual.

\section{Contextualização da educação superior no Brasil}

Historicamente, observamos que os primeiros passos para a constituição da educação superior brasileira datam de 1572, com a criação dos cursos de Artes e Teologia no Colégio dos Jesuítas da Bahia. Posteriormente, em 1759, ocorreu a abertura de aulas de matérias isoladas, até que, em 1776, criou-se uma faculdade no Seminário dos Franciscanos no Rio de Janeiro e, em 1798, no Seminário de Olinda (BARREYRO, 2008).

Um dos eventos marcantes para a ampliação da educação no país foi à transferência da sede do império português para o Brasil, momento que a educação superior toma características não-religiosas. A partir de 1808, foram instalados cursos superiores no Rio de Janeiro, com o intuito de suprir as necessidades do Estado, bem como a formação de profissionais para a burocracia e de profissionais liberais (BARREYRO, 2008).

A partir do século XIX, o desenvolvimento da educação superior começou a ter os primeiros contornos, com vistas à formação profissional. Foi, especificamente após a Independência, que se institucionalizaram no Brasil dois setores: o do ensino estatal e o do ensino particular. Nesse cenário, só se pode falar em educação superior privada no Brasil após a República, pois a Constituição de 1891 descentralizou a educação superior, o que permitiu a criação de instituições privadas (SAMPAIO, 2000).

Aliás, a criação de escolas superiores particulares permitiu a ampliação da educação superior no país. Assim, se em 1880 havia 2.300 mil estudantes, em 1915 somavam mais de 10 mil matrículas. Em 1930, havia quase 20 mil alunos. Entre 1892 e 1910, foram criadas 27 Instituições de Ensino Superior (IES), (BARREYRO, 2008).

No bojo dessa trajetória, é possível perceber que no final do século XIX duas correntes filosóficas se estabeleceram no campo educacional - a positivista que se manifestava contra a criação de uma universidade e a corrente liberal, que se manifestava a favor. Dessa forma, em 1920 é criada a universidade do Rio de Janeiro, o que abriu caminho para o surgimento de 
outras instituições, a exemplo da Universidade de Minas Gerais (1927), da Universidade do Rio Grande do Sul (1932), da Universidade de São Paulo (1934), e da Universidade do Distrito Federal (1935).

O debate acerca da educação superior intensificou-se na década de 1940 e teve como importantes atores os estudantes, por meio da União Nacional dos Estudantes - UNE. Surgiu, assim, a reivindicação pela universidade pública, gratuita e de qualidade, que visava à democratização e à ampliação do acesso, à atenuação do rigor nos exames vestibulares, assim como à proposta de universidade a serviço da sociedade (BARREYRO, 2008).

Após 1945, o desenvolvimento da educação superior foi ampliado de forma significativa, com o registro de 27.253 matrículas. Após duas décadas, em 1964, esse número se expandiu para 142.386 (CUNHA, 1983). Cabe assinalar, como fatos relevantes do período, a aprovação da primeira LDB em 1961, da Constituição de 1946 e sua legislação complementar, que definiu normas para a autorização e reconhecimento das IES (SAMPAIO, 2000).

Paralelamente à aprovação da LDB, estava em pauta nas discussões do movimento estudantil a necessidade de uma reforma universitária que gerou a "Carta da Bahia" com as seguintes diretrizes: quebra das barreiras entre as faculdades; criação de institutos; organização do regime departamental e do trabalho docente e discente em tempo integral; extinção da cátedra vitalícia (CUNHA, 1983).

A mobilização estudantil no início de 1968, caracterizada por intensos debates no âmbito das universidades e por manifestações de rua, passou a exigir do Governo soluções para os problemas educacionais. A resposta de maior alcance foi à criação do Grupo de Trabalho (GT), pelo Decreto $\mathrm{n}^{\circ}$ 62.937, de 02 de julho de 1968, encarregado de estudaras medidas que deveriam ser tomadas para resolver a chamada "crise da Universidade". Esse foi o marco para a reestruturação das universidades brasileiras, a fim de romper com estrutura anacrônica até então presente em seu cerne, que a impedia de desenvolver-se (FÁVERO, 2006).

A Lei $n^{\circ} 5.5401968$ (BRASIL, 1968), que versa sobre a reforma universitária foi elaborada objetivando levar a universidade brasileira à reformulação e à atualização dos seus objetivos, da sua estrutura acadêmica didática e administrativa (ANTUNES, 2012). Essa lei promulgou a indissociabilidade entre ensino, pesquisa e extensão, como atividades a serem realizadas nas universidades. Se por um lado, a reforma universitária recuperou algumas reivindicações dos estudantes na década anterior, por outro, a lógica de funcionamento foi 
estabelecida de acordo com o modelo socioeconômico, que buscava a ampliação do acesso à educação superior.

Na década de 1970, período inicial da reforma universitária, a educação superior passou por um processo acentuado de expansão dos cursos, das universidades e das vagas ofertadas, realizada predominantemente pela iniciativa privada. Com esse movimento desencadeado entre 1970 e 1980, professores recém-formados foram contratados para ministrar cursos com número excessivo de alunos por turma e sem o desenvolvimento de pesquisas. Pode-se pensar que, tais características foram responsáveis pela baixa qualidade da educação superior nesse período (SILVA JÚNIOR; SGUISSARDI, 2001; BARREYRO, 2008).

Posteriormente, a Constituição Federal de 1988 destacou-se como um importante marco na história do país que e a educação superior passou a ser regulamentada, juntamente com a homologação de leis complementares, buscando atender ao mercado na qualificação profissional (ANTUNES, 2012).

Convém observar que, no início da década de 1990, o país começou a adaptar-se ao modelo neoliberal. Nessa conjuntura, dobrou-se o número de universidades privadas, diminuiu-se o número de estabelecimentos isolados e aumentou-se o número de federações de escolas. A Constituição Federal de 1988, e depois a LDB de 1996, que lhes outorgaram autonomia e maior flexibilidade na gestão.

Dados apresentados no MEC/INEP demonstram o crescimento do número de matrículas por categoria administrativa no período de 1964-1994, conforme exposto na Tabela 1.

Tabela 1 - Número de matrículas na educação superior brasileira entre 1964-1994, por categoria administrativa

\begin{tabular}{llllll}
\hline Ano & \multirow{2}{*}{ Total } & $\begin{array}{l}\text { Público } \\
\text { n. }\end{array}$ & \% & $\begin{array}{l}\text { Privado } \\
\text { n. }\end{array}$ & \% \\
\hline $\mathbf{1 9 6 4}$ & 142.386 & 87.665 & 61,5 & 54.721 & 38,5 \\
$\mathbf{1 9 7 4}$ & 937.593 & 341.028 & 36,5 & 596.565 & 63,5 \\
$\mathbf{1 9 8 4}$ & 1.399 .539 & 571.879 & 41 & 827.660 & 59 \\
$\mathbf{1 9 9 4}$ & 1.661 .034 & 690.450 & 42 & 970.584 & 58 \\
\hline
\end{tabular}

Fonte: Adaptado do MEC/INEP/DEED. Sinopse Estatística da Educação Superior.

Pode-se observar que, no período anterior a reforma universitária, predominavam-se matrículas em IES públicas $(61,5 \%)$. Após a reforma, nota-se um crescimento expressivo no número de matrículas, tanto em IES públicas como privadas. Entre as décadas de 1964 e 
1974, as IES públicas apresentaram aumento de $290 \%$ nas matrículas, enquanto as privadas apresentaram crescimento de 990\%, invertendo-se as proporções da década anterior. Constatou-se, assim, um total geral de $560 \%$ de crescimento das matrículas em 10 anos (1964-1974).

No período de 1974 a 1984, foi possível identificar contínuo incremento no número de matrículas das IES, representadas por aumento semelhante entre públicas e privadas, mas, manteve-se a maior oferta pelas IES privadas (59\%). Ao longo das décadas de 1984 a 1994, o aumento das matrículas da educação superior foi menor $(18,7 \%)$, mantendo-se praticamente inalterada a proporção entre a oferta das matrículas públicas e privadas.

Ademais, modificações continuaram a ocorrer na educação superior. Na década de 1990, a partir do Decreto ${ }^{\circ}$ 2.306/97 que dispõe sobre a diversificação das instituições, se tornou possível à criação de diferentes instituições acadêmicas autorizadas a ministrar educação superior, quais sejam: centros universitários, faculdades integradas, faculdades e institutos ou escolas superiores. Essas instituições podem formar, mas não precisam desenvolver as funções indissociáveis (ensino, pesquisa, extensão), obrigatórias às universidades.

Portanto, a expansão da educação superior brasileira foi expressiva nessa década, em que ocorreram reformas direcionadas ao desenvolvimento do mercado. Diante disso, o setor educacional passou por alterações significativas, tanto na forma de organização, como nas condições de funcionamento e de trabalho dos docentes (ANTUNES, 2012).

Sedimenta-se então, um intenso processo de mercantilização dos serviços educacionais, de intensificação do trabalho docente e de precarização do trabalho. Esses fatores são discutidos, na sequência, com base em indicadores gerais da expansão da educação superior brasileira

\section{Indicadores gerais da expansão da educação superior brasileira a partir da década de 1990}

A partir da análise dos dados do Censo sistematizados e disponibilizados desde o ano de 1995 pelo MEC/INEP, verificar um processo de expansão da educação superior. O Quadro 1 apresenta os dados de crescimento da educação superior brasileira quanto ao quantitativo de IES, cursos de graduação, matrículas e docentes, entre os anos de 1995-2015 ${ }^{5}$.

\footnotetext{
${ }^{5} \mathrm{O}$ último Censo da Educação Superior publicado pelo INEP data o ano de 2015. Até o momento não foram organizados e disponibilizados os dados dos anos seguintes.
} 
Quadro 1 - Números de Instituições de Ensino Superior, cursos, matrículas e docentes entre 1995-2015, por categoria administrativa

\begin{tabular}{|c|c|c|c|c|c|c|c|c|c|c|c|c|}
\hline \multirow{2}{*}{ Ano } & \multicolumn{3}{|c|}{ Quantidade de IES } & \multicolumn{3}{|c|}{ Quantidade de Cursos } & \multicolumn{3}{|c|}{ Quantidade de Matrículas } & \multicolumn{3}{|c|}{ Quantidade de Docentes } \\
\hline & Pública & Privada & Total & Pública & Privada & Total & Pública & Privada & Total & Pública & Privada & Total \\
\hline 1995 & 210 & 684 & 894 & 2.782 & 3.470 & 6.252 & 700.540 & 1.059 .163 & 1.759 .703 & 76.268 & 69.022 & 145.290 \\
\hline 1996 & 211 & 711 & 922 & 2.978 & 3.666 & 6.644 & 735.427 & 1.133 .102 & 1.868 .529 & 74.666 & 73.654 & 148.320 \\
\hline 1997 & 211 & 689 & 900 & 2.698 & 3.434 & 6.132 & 759.182 & 1.186 .433 & 1.945 .615 & 84.591 & 81.373 & 165.964 \\
\hline 1998 & 209 & 764 & 973 & 2.970 & 3.980 & 6.950 & 804.729 & 1.321 .229 & 2.125 .958 & 83.738 & 81.384 & 165.122 \\
\hline 1999 & 192 & 905 & 1.097 & 3.494 & 5.384 & 8.878 & 832.022 & 1.537 .923 & 2.369 .945 & 80.883 & 92.953 & 173.836 \\
\hline 2000 & 176 & 1.004 & 1.180 & 4.021 & 6.564 & 10.585 & 887.026 & 1.807 .219 & 2.694 .245 & 88.154 & 109.558 & 197.712 \\
\hline 2001 & 183 & 1.208 & 1.391 & 4.401 & 7.754 & 12.155 & 939.225 & 2.091 .529 & 3.030 .754 & 90.950 & 128.997 & 219.947 \\
\hline 2002 & 195 & 1.442 & 1.637 & 5.252 & 9.147 & 14.399 & 1.051 .652 & 2.428 .258 & 3.479 .913 & 84.006 & 143.838 & 227.844 \\
\hline 2003 & 207 & 1.652 & 1.859 & 5.662 & 10.791 & 16.453 & 1.136 .370 & 2.750 .652 & 3.887 .022 & 88.795 & 165.358 & 254.153 \\
\hline 2004 & 224 & 1.789 & 2.013 & 6.262 & 12.382 & 18.644 & 1.178 .328 & 2.985 .405 & 4.163 .733 & 93.800 & 185.258 & 279.058 \\
\hline 2005 & 231 & 1.934 & 2.165 & 6.191 & 14.216 & 20.407 & 1.192 .189 & 3.260 .967 & 4.453 .156 & 98.033 & 194.471 & 292.504 \\
\hline 2006 & 248 & 2.022 & 2.270 & 6.549 & 15.552 & 22.101 & 1.209 .304 & 3.467 .342 & 4.676 .646 & 100.726 & 201.280 & 302.006 \\
\hline 2007 & 249 & 2.032 & 2.281 & 6.596 & 16.892 & 23.488 & 1.240 .968 & 3.639 .413 & 4.880 .381 & 108.828 & 208.213 & 317.041 \\
\hline 2008 & 236 & 2.016 & 2.252 & 6.772 & 17.974 & 24.719 & 1.273 .965 & 3.806 .091 & 5.080 .056 & 111.894 & 209.599 & 321.493 \\
\hline 2009 & 245 & 2.069 & 2.314 & 8.228 & 19.599 & 27.827 & 1.351 .168 & 3.764 .728 & 5.115 .896 & 122.977 & 217.840 & 340.817 \\
\hline 2010 & 278 & 2.100 & 2.378 & 8.821 & 19.756 & 28.577 & 1.461 .696 & 3.987 .424 & 5.449 .120 & 130.789 & 214.546 & 345.335 \\
\hline 2011 & 284 & 2.081 & 2.365 & 9.368 & 20.008 & 29.376 & 1.595 .391 & 4.151 .371 & 5.746 .762 & 139.584 & 217.834 & 357.418 \\
\hline 2012 & 304 & 2.112 & 2.416 & 10.394 & 20.324 & 30.718 & 1.715 .752 & 4.208 .086 & 5.923 .838 & 150.338 & 212.394 & 362.732 \\
\hline 2013 & 301 & 2.090 & 2.391 & 10.344 & 20.447 & 30.791 & 1.777 .974 & 4.374 .431 & 6.152 .405 & 155.219 & 212.063 & 367.282 \\
\hline 2014 & 298 & 2.070 & 2.368 & 10.609 & 20.904 & 31.513 & 1.821 .629 & 4.664 .542 & 6.484 .171 & 163.113 & 220.273 & 383.386 \\
\hline 2015 & 295 & 2.069 & 2.364 & 10.347 & 21.681 & 32.028 & 1.823 .752 & 4.809 .793 & 6.633 .545 & 165.722 & 222.282 & 388.004 \\
\hline
\end{tabular}

Fonte: Adaptado do MEC/INEP/DEED. Sinopse Estatística da Educação Superior. 
A partir de informações obtidas sobre o período de 1995-2015, análises foram tecidas a respeito do crescimento da educação superior no Brasil ao longo de 20 anos.

Em se tratando do quantitativo de IES, percebe-se um acréscimo de 142\% em 10 anos (1995-2005), representado principalmente pelo setor privado (183\%). O aumento mais expressivo foi entre os anos de 2000 e 2003. Em contrapartida, o crescimento no setor público foi tímido nestes anos (10\%). Após 2007, tem-se uma tendência à estagnação, considerando que o percentual de aumento do número de IES no Brasil foi de 9\%. Contudo, outros contornos ficam claros numa comparação entre os setores público e privado nesse período, pois fica evidente que a estagnação está presente no setor privado (7\%), já que o ensino público cresceu $30 \%$.

Constata-se, portanto, descompassos entre a ampliação das IES públicas e privadas. A expansão da educação superior se deu, majoritariamente, pelo setor privado que cresceu exponencialmente até 2007, mas, posteriormente apresentou características de estagnação. Enquanto isso, o setor público desenvolveu-se de forma constante, embora também demonstre desgastes no crescimento dos últimos anos analisados.

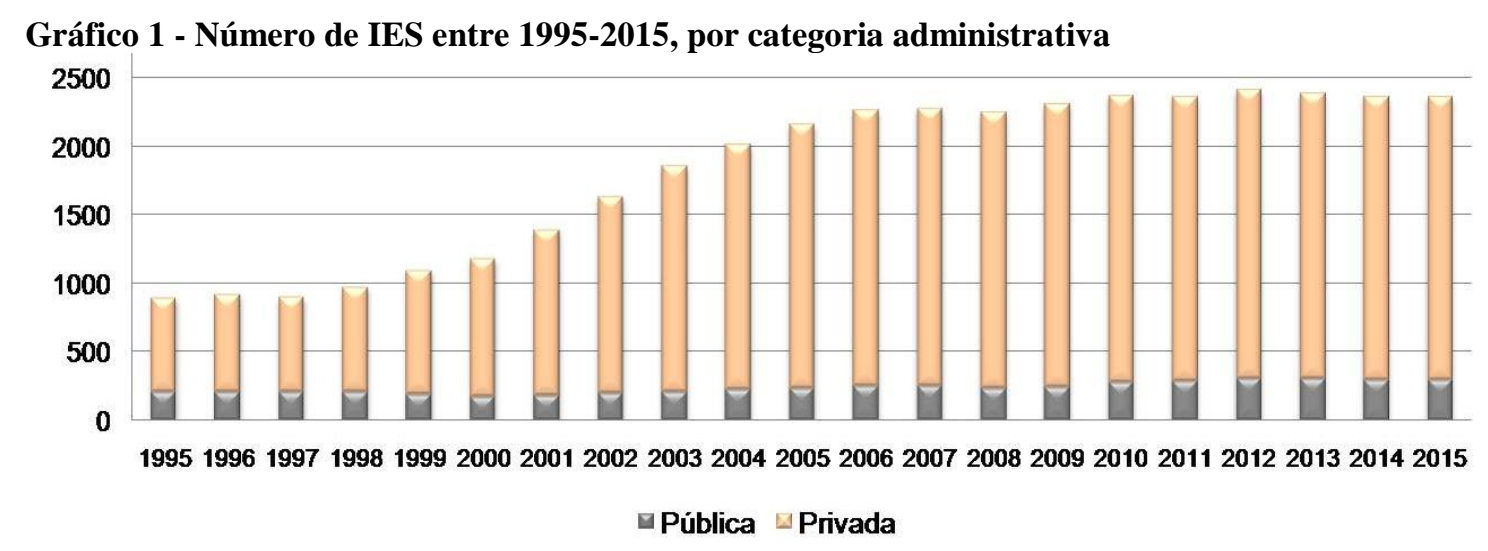

Fonte: As autoras.

Quanto ao número de cursos de graduação presencial, identifica-se um aumento expressivo somente no final da década de 1990. Ainda assim, a primeira década analisada foi marcada por um aumento de $226 \%$ no quantitativo de cursos ofertados, com predomínio em IES privadas (310\%). Após 2005, a ampliação foi de 57\%, representada de forma mais significativa pelo setor público $(67 \%)$, do que pelo setor privado $(52 \%)$. Mas, do ponto de vista dos cursos, ambos setores desenvolveram-se, conforme demonstra o Gráfico 2. 
Gráfico 2 - Número de cursos de graduação entre 1995-2015, por categoria administrativa

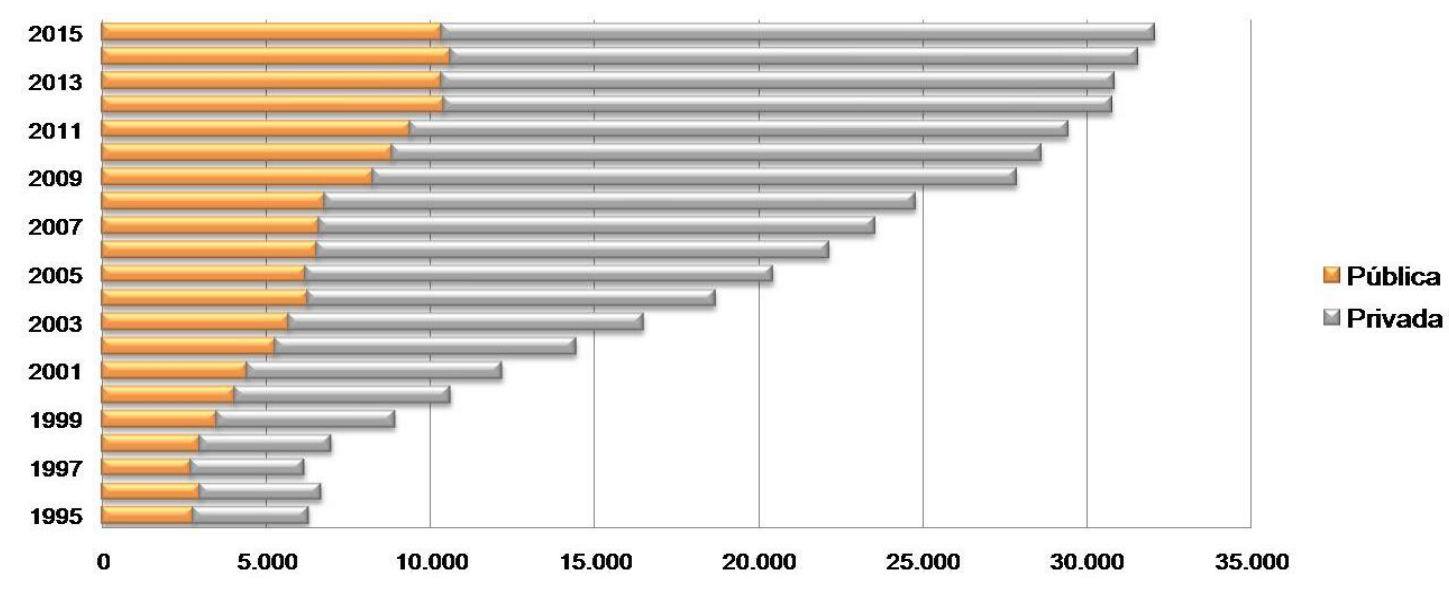

Fonte: As autoras.

O número de matrículas também se ampliou de forma expressiva entre 1995-2005 (153\%), com destaque para o setor privado (208\%) nesse período. Em menor escala, mas não menos significativa, o setor público apresentou acréscimo no número de matrículas $(70 \%)$. Entre 2005-2015, esse percentual sofreu alterações, demonstrando um crescimento total relativamente menor (42\%). Convém observar que nesse período ambos setores apresentaram ampliação equiparada no quantitativo de matrículas (53\% e $47 \%$ respectivamente).

A propósito, os dados revelam que, embora tenha ocorrido uma estagnação na ampliação de IES no Brasil, o número de matrículas continuou a crescer ao longo das duas décadas. Tal análise sugere que as IES ampliaram sua estrutura para ofertar mais cursos e para abranger um maior número de vagas. Vale salientar que, nos últimos anos se observou alargamento da oferta de matrículas pelo setor público, enquanto a oferta de matrículas pelo setor privado teve uma redução significativa. Ainda assim, esses números continuaram em expansão (Gráfico 3).

Gráfico 3 - Número de matrículas em cursos presenciais entre 1995-2015, por categoria administrativa

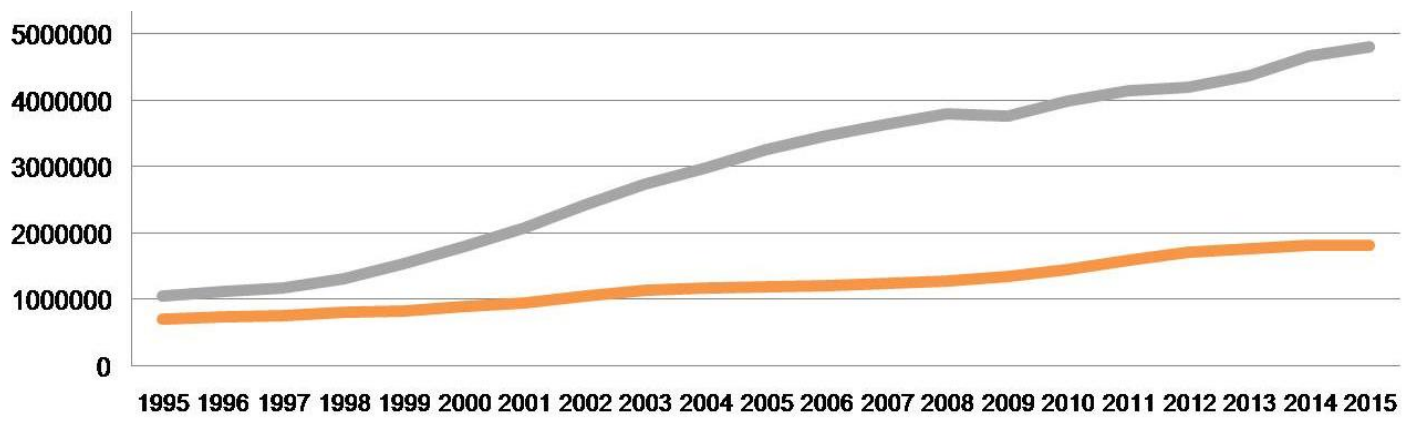

- Pública - Privada

Fonte: As autoras. 
Os achados sobre a inserção de docentes em IES brasileiras chamam a atenção. O acréscimo do corpo docente foi de $101 \%$ de $1995-2005$, caracterizados por $182 \%$ no setor privado e $28 \%$ no público. Entre 2005-2015, o crescimento total foi de 33\%, revelando descompassos com a década anterior, já que desta vez o setor público destacou-se (67\%), enquanto no setor privado, o percentual da admissão de docentes foi significativamente menor (14\%), conforme exposto no Gráfico 4.

Gráfico 4 - Número de docentes entre 1995-2015, por categoria administrativa

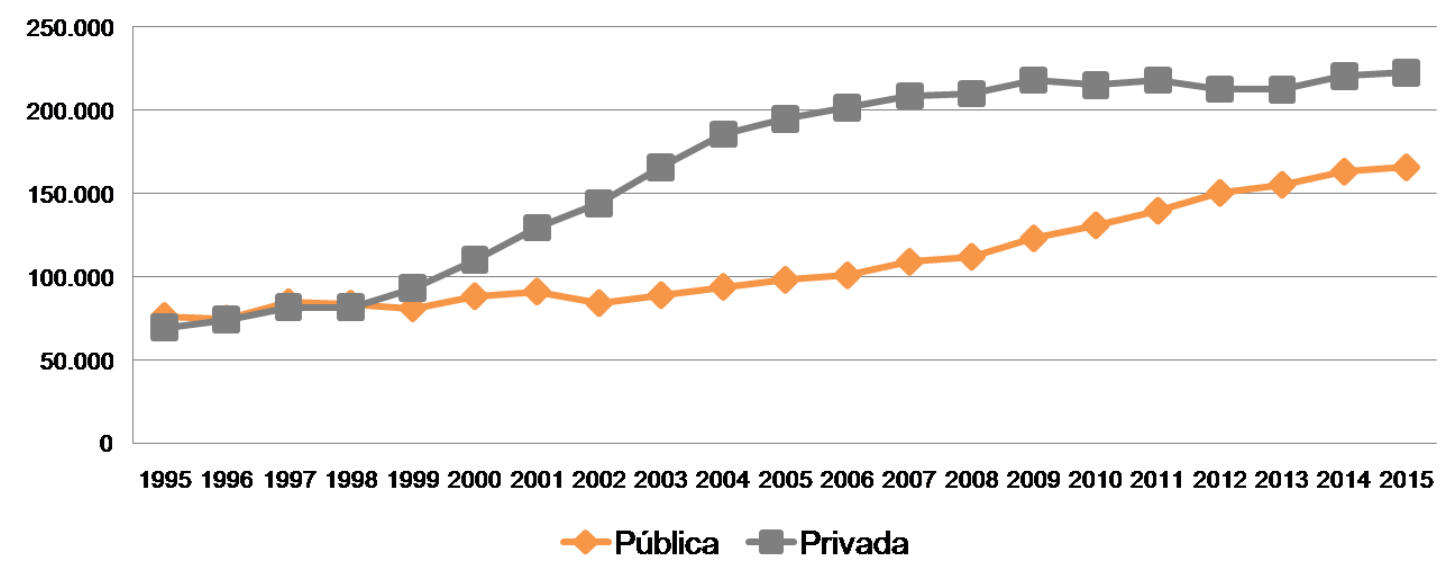

Fonte: As autoras.

Esse conjunto de indicadores apresenta indícios de que a expansão da educação superior brasileira foi predominantemente privada e marcada por uma série de discrepâncias (INEP, 2015). Dessa forma, os dados dão pistas de que estamos diante, também, de um processo de ampliação do campo profissional da docência universitária.

Mais informações são acrescentadas a esse diagnóstico quando verifica-se relação entre o quantitativo de matrículas e o quantitativo de docentes, pois, o crescimento exponencial de matrículas de alunos precisa vir acompanhado do aumento da admissão de docentes para atender a essa demanda. Nesse sentido, o Quadro 2 traz a relação dessas categorias entre os anos de 1995-2015.

Quadro 2 - Relação matrículas/docente entre 1995-2015, por categoria administrativa

\begin{tabular}{|l|l|l|l|}
\hline Ano & Pública & Privada & Total \\
\hline $\mathbf{1 9 9 5}$ & 9,2 & 15,3 & 12,1 \\
\hline $\mathbf{2 0 0 0}$ & 11,3 & 17,3 & 14,7 \\
\hline $\mathbf{2 0 0 5}$ & 12,2 & 16,8 & 15,2 \\
\hline $\mathbf{2 0 1 0}$ & 11,2 & 18,6 & 15,8 \\
\hline $\mathbf{2 0 1 5}$ & 11 & 21,6 & 17,1 \\
\hline
\end{tabular}

Fonte: Adaptado do MEC/INEP/DEED. Sinopse Estatística da Educação Superior 
Ao se relacionar as categorias quantitativo de matrículas e admissão de docentes, evidenciam-se dissonâncias quanto às condições de trabalho em IES públicas e privadas. Isso porque, no período de 1995-2015, a média no setor público foi de 11 matrículas/docente e no setor privado 18 matrículas/docente.

É oportuno observar que, quanto menor a relação entre essas categorias, maiores são as chances de uma formação qualificada. No entanto, dados de 2015 revelaram que a relação matrícula/docente continuou a crescerem IES privadas $(n=21,6)$. Já em IES públicas, o índice diminuiu a cada ano $(n=11)$. No setor público, a menor relação entre essas categorias justificase pelo aumento da contratação de docentes.

A situação retratada revela pontos ainda mais críticos quando se verifica o tipo de regime de trabalho dos docentes das instituições públicas e privadas. Dados do censo (INEP, 2014, 2015) demonstraram predominância do regime de tempo integral no setor público (84\%). No setor privado, tem-se predomínio dos regimes de trabalho de tempo parcial e horista (75\%). É válido mencionar que em 2014, pela primeira vez, as funções docentes do setor privado em tempo parcial superaram os horistas, ao passo que, no setor público, o número de funções docentes em tempo integral aumento de forma significativa nos últimos anos.

Antes de o sistema educacional revelar dados concretos de disparidade na relação matrícula/docente, análises já alertavam que a desordenada expansão e o agressivo jogo do mercado educacional trariam problemas para os docentes brasileiros e que, na sensível crise financeira das IES privadas da época, sinais foram emitidos de que os bons níveis salariais do setor privado iriam cair (GIOLO, 2006).

Sguissardi (2008b) indicou que a concepção da educação superior, como bem público, é, na prática, bem de serviço privado, considerando seu modelo de expansão que privilegia a oferta por empresas privadas/mercantis.

\section{Desafios para o trabalho docente}

Fato é que, a conjuntura atual apresenta uma série de problemáticas nas condições de trabalho docente. $\mathrm{O}$ intenso processo de privatização desencadeado a partir da década de 1990, impactou duplamente o trabalho docente - em seu regime de trabalho e em sua produção (o ensino e a pesquisa), acarretando implicações para o ensino em nível superior como um todo (MANCEBO et al., 2006). 
Portanto, as tentativas de compreensão da atual conjuntura do ensino em nível superior e das condições de trabalho dos docentes que nele se inserem requerem que as modificações do sistema econômico, político, social e educacional sejam consideradas.

Isaia (2006, p. 64) destaca como modificações contemporâneas:

[...] de um bem cultural, a universidade passou a ser um bem econômico; de um lugar reservado a poucos, tornou-se um lugar para o maior número possível de pessoas; de um bem direcionado ao aprimoramento de indivíduos, tornou-se um bem cujo beneficiário é o conjunto da sociedade; e, ainda, transformou-se em mais um recurso do desenvolvimento social e econômico dos países, submetendo-se às mesmas leis políticas e econômicas; faz parte das dinâmicas sociais e está sujeita aos mesmos processos e às mesmas incertezas do âmbito político, econômico ou cultural que afetam todas as instituições sociais.

Pesquisadores alertam que a educação superior tem se amoldado a lógica do mercado, que de educação de direito tem sido transformada em prestadora de serviço, configurando-se como uma organização empresarial em detrimento de sua constituição inicial como instituição social (BRANDÃO; FERENC; BRAÚNA, 2015). Consequentemente, tais alterações têm conduzido a uma mercantilização dos serviços educacionais, uma precarização do trabalho dos docentes universitários e provocado mudanças decisivas em sua atuação e função social (SEVERINO, 2009).

Bosi (2007) acrescenta que no processo de expansão da educação superior, o desenvolvimento da força de trabalho docente foi marcado pela flexibilização dos contratos trabalhistas. E que as possibilidades de contratação precária, abertas por práticas constituídas à margem da lei ou por modificações na legislação trabalhista que corroboraram para que o quantitativo de docentes aumentasse. Além disso, inúmeras mudanças foram introduzidas na rotina das atividades de ensino, pesquisa e extensão.

A propósito, no atual contexto de expansão da educação superior, a pós-graduação e a produção do conhecimento desenvolveram-se, acompanhadas de um acréscimo de investimento das agências governamentais, e maior exigência na produção científica, que resultaram em maior produtividade para o Brasil (MORAES; AZEVEDO; CATANI, 2014). Outras problemáticas surgem como o ajustamento cada vez maior das produções às exigências do sistema produtivo, o que traz preocupações com a natureza e com o caráter dessa produção do conhecimento, uma vez que pode atender mais as demandas econômicas, do que propriamente as demandas sociais.

Diante desse novo cenário da educação superior brasileira, o documento "Desafios e perspectivas da educação superior brasileira para a próxima década: 2011-2020" (UNESCO, 2012), elegeu como desafios: a) a democratização do acesso e da permanência na educação 
superior; b) a ampliação da rede pública superior e de vagas; c) a redução das desigualdades regionais quanto ao acesso; d) a formação com qualidade; e) a diversificação da oferta de cursos e dos níveis de formação; f) a qualificação dos docentes; g) a garantia de financiamento; h) a relevância social dos programas oferecidos e i) o estímulo a pesquisa científica e tecnológica.

Debatendo essa temática, Sguissardi (2008a) esclarece que, aquilo que está em jogo é a qualidade da educação superior e do trabalho docente. Isso porque, o modelo de expansão brasileiro se caracteriza por uma acelerada mercantilização, crescentemente marcado pelo predomínio dos interesses privados que desafiam a regulação estatal de caráter público e acabam comprometendo a formação em nível superior.

Aliás, é possível observar que, de um ensino para uma elite, com rigorosa seleção que facilitava a perpetuação de um determinado patrimônio do saber, passou-se para outro caminho, em que o aumento do número de alunos provocou uma transformação da sua própria missão. O processo formativo tornou-se menos eficaz num contexto de tamanha expansão, se comparado aquele destinado a poucos estudantes (GARCIA, 2001).

Atualmente, um dos principais objetivos das IES, especificamente das privadas, é a extração máxima de lucro, que em muitos casos, sacrifica as condições do trabalho e a qualidade do ensino ofertado (NUNES; NEIRA, 2014; SEVERINO, 2009; SGUISSARDI, 2015).

Obviamente, a concepção de qualidade é tomada como um conceito abstrato, essencialista, pelos discursos oficiais e incorporados no senso comum. No entanto, esta luta acaba por ocultar a ação de um arbitrário cultural que está na base do status e da distinção que separam os melhores dos piores (BOURDIEU, 1983).

O encontro entre as categorias quantidade/qualidade e educação superior só é possível mediante a construção de um projeto político acadêmico-científico articulado de forma eficaz no contexto das instituições universitárias. Portanto, é necessário pensar qual é o tipo de universidade que se almeja e que a realidade brasileira necessita. Esse é um ponto de partida importante para se projetarem que medida essas instituições poderão ser ampliadas. A expansão da educação superior deve ser entendida como um processo pelo qual a quantidade se transforma em qualidade e vice-versa (FÁVERO; SGUISSARDI, 2012).

[...] Faz-se necessário um debate mais amplo acerca das funções e do papel exercido pela educação superior no país, assim como o de suas instituições, quanto à sua capacidade de atender a demandas de conhecimento e de formação advindas do processo de desenvolvimento socioeconômico, científico e tecnológico (UNESCO, 2012, p. 12). 
Nessa ótica, Sguissardi (2015) põe em questão o caráter democrático da expansão da educação superior brasileira, pois, de um lado, mantêm-se de elite e de alta qualificação para poucos, e, de outro, como de massificação e de baixa qualificação para muitos, colocando em xeque o alcance da sua efetiva democratização.

Por isso mesmo, as bases para o enfrentamento dos desafios relativos à educação superior brasileira precisam ser problematizadas e pressupõem iniciativas conjuntas de instituições, docentes e alunos, em consonância com as políticas de educação superior, o que pode impactar positivamente no desenvolvimento institucional e profissional daqueles que labutam nesse nível de ensino.

\section{Considerações finais}

Contextualizado o cenário da expansão da educação superior no Brasil, é possível compilar um conjunto de aspectos relevantes e, ao mesmo tempo preocupantes, quanto aos decisivos impactos das transformações ocorridas nas últimas décadas para o campo educacional como um todo.

A partir desse panorama, constata-se que, semelhantemente ao que já vinha ocorrendo em larga escala desde a década de 1970, o Brasil continuou a apresentar constante ascensão nos números totais na década de 1990. Esse período se consolidou pelo boom de criação de instituições superiores, de oferta de cursos de graduação e de matrículas. No entanto, essa expansão ocorre de forma desordenada, a exemplo do que se verificou na primeira metade dessa década, quando a relação de matrículas no setor privado apresentou incremento significativo, ao ser comparada com o setor público.

Todavia, após 2005, um novo cenário começou a ser estruturado no âmbito da educação superior brasileira. A medida que a oferta de cursos e de matrículas continuou em ascensão, esse crescimento foi significativamente menor que na década anterior. Ademais, houve uma estagnação do quantitativo de IES, ao passo que pouca modificação foi identificada na admissão de docentes do setor privado, revelando baixos índices de crescimento dos números totais se comparado ao crescimento da década de 1990.

Embora esse desenvolvimento apresente aspectos positivos para o país, não se pode desconsiderar os impactos da expansão para o cotidiano de trabalho dos docentes universitários, que têm enfrentado uma série de problemáticas no desempenho de suas funções, além da evidente precarização nas condições de trabalho. Além do mais, importa 
destacar que, outros aspectos que indiquem a conjuntura da educação superior brasileira necessitam ser tratados e analisados pela comunidade acadêmica.

\section{Referências}

ALMEIDA SANTOS, Valéria. Pesquisa e metodologias (módulo de ensino). Itabuna, 2006.

ANTUNES, Natália Silveira. Expansão da educação superior: o contexto dos cursos de educação física no Brasil. 2012. 100 f. Dissertação (Mestrado em Educação Física) Universidade Federal de Pelotas, Rio Grande do Sul, 2012.

BARREYRO, Gladys Beatriz. Mapa do ensino superior privado. Brasília: INEP, 2008.

BOSI, Antônio de Pádua. A precarização do trabalho docente nas instituições de ensino superior no Brasil nesses últimos 25 anos. Revista Educação \& Sociedade, Campinas, v. 28, n. 101, p. 1503-1523, set./dez., 2007. Disponível em: https://www.scielo.br/scielo.php?pid=S010173302007000400012\&script=sci_arttext. Acesso em: 15 maio 2020.

BOURDIEU, Pierre. Questões de sociologia. Rio de Janeiro: Marco Zero, 1983.

BRANDÃO, Ana Carolina Pessoa; FERENC, Alvanize Valente Fernandes; BRAÚNA, Rita de Cássia Alcântara. Condições de trabalho docente na universidade pública brasileira: um mapeamento de estudos. Espaço Pedagógico, Passo Fundo, v. 22, n. 2, p. 343-355, jul./dez. 2015. Disponível em: http://seer.upf.br/index.php/rep/article/view/5561. Acesso em: 15 maio 2020.

BRASIL. Lei nº 5.540/1968. Lei da reforma universitária. Brasília,1968.

BRASIL. Lei nº 9.394/96. Lei de Diretrizes e Bases da Educação Nacional. Diário Oficial da União, Brasília, 23 dez. 1996.

CUNHA, Luiz Antônio. A universidade crítica. Rio de Janeiro: Francisco Alves, 1983.

FÁVERO, Maria de Lourdes. A universidade no Brasil: das origens à Reforma Universitária de 1968. Educar, Curitiba, n. 28, p. 17-36, 2006.

FÁVERO, Maria de Lourdes; SGUISSARDI, V. Quantidade/qualidade e educação superior. Educação em Questão, Natal, v. 42, n. 28, p. 61-88, jan./abr. 2012.

FRANCO, Thais de Andrade Vidaurre; DAL POZ, Mario Roberto. A participação de Instituições de Ensino Superior privadas na formação em saúde no Brasil. Trabalho, Educação e Saúde, Rio de Janeiro, v. 16, n. 3, p. 1017-1037, 2018. Disponível em: https://www.scielo.br/scielo.php?script=sci arttext\&pid=S1981-77462018000301017. Acesso em: 15 maio 2020. 
GARCIA, Rui Proença. Para um ensino superior com qualidade. Revista Portuguesa de Ciências do Desporto, Portugal, v. 1, n. 1, p. 33-43, 2001.

GIOLO, Jaime. Os docentes da educação superior brasileira. In: RISTOFF, Dilvo; SEVEGNANI, Palmira (org.). Docência na educação superior. INEP: Instituto Nacional de Estudos e Pesquisas Educacionais Anísio Teixeira. Coleção Educação Superior em Debate, v. 5, 2006. p. 19-46.

INSTITUTO NACIONAL DE ESTUDOS E PESQUISAS EDUCACIONAIS ANÍSIO TEIXEIRA (Inep). Censo da Educação superior 2014. Sinopse Estatística. Brasília, 2015.

INSTITUTO NACIONAL DE ESTUDOS E PESQUISAS EDUCACIONAIS ANÍSIO TEIXEIRA (Inep). Censo da Educação superior 2015. Sinopse Estatística. Brasília, 2016.

ISAIA, Silvia Maria de Aguiar. Desafios à docência superior pressupostos a considerar. In: RISTOFF, Dilvo; SEVEGNANI, Palmira (org.). Docência na educação superior. INEP: Instituto Nacional de Estudos e Pesquisas Educacionais Anísio Teixeira. Coleção Educação Superior em Debate, v.5, 2006. p. 63-84.

LAKATOS, Eva Maria; MARCONI, Marina de Andrade. Metodologia do trabalho científico: procedimentos básicos, pesquisa bibliográfica, projeto e relatório, publicações de trabalhos científicos. São Paulo, Atlas, 2012.

MANCEBO, Deise et al. Crise e reforma do Estado: e da Universidade Brasileira: implicações para o trabalho docente. Educar em Revista, Curitiba, n. 28, p. 37-53, 2006. Disponível em: https://www.scielo.br/scielo.php?pid=S0104-40602006000200004\&script=sci_arttext. Acesso em: 15 maio 2020.

MORAES, Karine Nunes de; AZEVEDO, Mário Luiz Neves de; CATANI, Afrânio Mendes. A produção do conhecimento no contexto das políticas de expansão da educação superior no Brasil pós-LDB/1996: uma síntese. Revista Eletrônica de Educação, São Carlos, v. 8, n. 1, p. 119-132, 2014. Disponível em: http://www.reveduc.ufscar.br/index.php/reveduc/article/view/1017. Acesso em: 15 maio 2020.

NUNES, Mário Luiz Ferrari; NEIRA, Marcos Garcia. Processos de inclusão excludente presentes no ensino superior privado. Educação \& Realidade, Porto Alegre, v. 39, n. 4, p. 1209-1228, out./dez. 2014. Disponível em: https://seer.ufrgs.br/educacaoerealidade/article/view/41858. Acesso em: 15 maio 2020.

SAMPAIO, Helena. O ensino superior no Brasil: o setor privado. São Paulo: Hucitec, Fapesp, 2000.

SANTOS, Ana Lúcia Padrão dos; SIMÕES, Antonio Carlos. Desafios do ensino superior em educação física: considerações sobre a política de avaliação dos cursos. Ensaio, Rio de Janeiro, v. 16, n. 59, p. 259-274, abr./jun. 2008.

SEVERINO, Antônio Joaquim. Expansão do ensino superior: contextos, desafios, possibilidades. Avaliação, Campinas; Sorocaba, v. 14, n. 2, p. 253-266, 2009. Disponível em: https://www.scielo.br/pdf/aval/v14n2/a02v14n2.pdf. Acesso em: 15 maio 2020. 
SGUISSARDI, Valdemar. Regulação estatal versus cultura de avaliação institucional? Avaliação, Campinas; Sorocaba, v. 13, n. 3, nov. 2008a. Disponível em:

https://www.scielo.br/pdf/aval/v13n3/16.pdf. Acesso em: 15 maio 2020.

SGUISSARDI, Valdemar. Modelo de expansão da educação superior no Brasil: predomínio privado/mercantil e desafios para a regulação e a formação universitária. Educação Social, Campinas, v. 29, n. 105, p. 991-1022, 2008b.

SGUISSARDI, Valdemar. Educação superior no Brasil: democratização ou massificação mercantil? Educação e Sociedade. Campinas, v. 36, n. 133, p. 867-889, out./dez. 2015.

Disponível em: https://www.scielo.br/scielo.php?pid=S0101-

73302015000400867\&script=sci_abstract\&tlng=pt. Acesso em: 15 maio 2020.

SILVA JÚNIOR, João dos Reis; SGUISSARDI, Valdemar. Novas faces da educação superior no Brasil: reformas do Estado e mudanças na produção. São Paulo: Cortez, 2001.

UNESCO. Desafios e perspectivas da educação superior brasileira para a próxima década: 2011-2020. Brasília: UNESCO, CNE, MEC, 2012.

UNESCO. Declaração mundial sobre educação euperior no século XXI: visão e ação. Brasília: UNESCO, CNE, MEC, 1998. 